$11-29-2021$

\title{
Transgender Attitudes and Beliefs Scale-Spanish (TABS-S) Version: Translation and Initial Evaluation of Psychometric Properties
}

Yasuko Kanamori

MSU Graduate Student

Eneritz Jiménez-Etxebarria

Jeffrey H. Cornelius-White

Missouri State University

Naiara Ozamiz-Etxebarria

Kelly N. Wynne

Missouri State University

See next page for additional authors

Follow this and additional works at: https://bearworks.missouristate.edu/articles-coe

\section{Recommended Citation}

Kanamori, Yasuko, Eneritz Jiménez-Etxebarria, Jeffrey HD Cornelius-White, Naiara Ozamiz-Etxebarria, Kelly N. Wynne, and Maitane Picaza Gorrotxategi. "Transgender Attitudes and Beliefs Scale-Spanish (TABS-S) Version: Translation and Initial Evaluation of Psychometric Properties." Journal of homosexuality (2021): 1-20.

This article or document was made available through BearWorks, the institutional repository of Missouri State University. The work contained in it may be protected by copyright and require permission of the copyright holder for reuse or redistribution.

For more information, please contact BearWorks@library.missouristate.edu. 


\section{Authors}

Yasuko Kanamori, Eneritz Jiménez-Etxebarria, Jeffrey H. Cornelius-White, Naiara Ozamiz-Etxebarria, Kelly N. Wynne, and Maitane Picaza Gorrotxategi 


\section{Journal of Homosexuality}

\section{Transgender Attitudes and Beliefs Scale-Spanish (TABS-S) Version: Translation and Initial Evaluation of Psychometric Properties}

Yasuko Kanamori, Eneritz Jiménez-Etxebarria, Jeffrey H. D. Cornelius-White, Naiara Ozamiz-Etxebarria, Kelly N. Wynne \& Maitane Picaza Gorrotxategi

To cite this article: Yasuko Kanamori, Eneritz Jiménez-Etxebarria, Jeffrey H. D. Cornelius-White, Naiara Ozamiz-Etxebarria, Kelly N. Wynne \& Maitane Picaza Gorrotxategi (2021): Transgender Attitudes and Beliefs Scale-Spanish (TABS-S) Version: Translation and Initial Evaluation of Psychometric Properties, Journal of Homosexuality, DOI: 10.1080/00918369.2021.2004797

To link to this article: https://doi.org/10.1080/00918369.2021.2004797

曲 Published online: 29 Nov 2021.

Submit your article to this journal $2 \pi$

Ш Article views: 15

Q View related articles $₫$

View Crossmark data $₫$ 


\title{
Transgender Attitudes and Beliefs Scale-Spanish (TABS-S) Version: Translation and Initial Evaluation of Psychometric Properties
}

\author{
Yasuko Kanamori, PhD (D) , Eneritz Jiménez-Etxebarria, $\mathrm{PhD}$ (D) $^{\mathrm{b}}$, \\ Jeffrey H. D. Cornelius-White, PsyD (D) ${ }^{a}$, Naiara Ozamiz-Etxebarria, PhD (D) ${ }^{\text {, }}$ \\ Kelly N. Wynne, PhD (D), and Maitane Picaza Gorrotxategi, PhD (iD ${ }^{c}$
}

\begin{abstract}
aDepartment of Counseling, Leadership, and Special Education, Missouri State University, Springfield, Missouri, USA; 'bepartment of Developmental and Educational Psychology, University of Basque Country, Leioa, Spain; ' Department of Didactics and School Organization, University of Basque Country, Leioa, Spain
\end{abstract}

\begin{abstract}
Although the field of transprejudice studies has been growing, the literature suggests a need for quality assessments in languages other than English. To address this need, our study translated the Transgender Attitudes and Beliefs Scale (TABS) and evaluated its psychometric properties for use with Spanishspeaking populations. We recruited participants $(N=605)$ from American and Spanish samples. Results of the confirmatory factor analysis showed adequate fit, confirming the three-factor structure of TABS-Spanish Version (TABS-S). Correlations with existing measures provided evidence for its convergent and discriminant validity. Known-groups validity of the TABS-S was evidenced through confirming previous findings that females show less transgender prejudice than males. Moreover, the internal consistency of the TABS-S scores was high for the total scale $(a=.96)$ and subscales $(a=.87-.96)$. Overall, there is preliminary evidence to suggest that the TABS-S is a valid and reliable scale appropriate for use with Spanish-speaking populations.
\end{abstract}

\section{KEYWORDS}

Transgender prejudice; Transgender Attitudes And Beliefs Scale; Spanish; validity; reliability; scale validation; transgender and gender non-conforming

\section{Introduction}

In recent years, there has been an increase in knowledge concerning attitudes toward transgender-identified individuals in English-speaking countries, such as the United States, Australia, and the United Kingdom (e.g., Kanamori, Cornelius-White, Pegors, Daniel, \& Hulgus, 2017; Riggs \& Sion, 2017; Westwood et al., 2020). This trend has been mirrored in non-English-speaking countries owning to translations of transgender attitudes scales into other languages (e.g., into Polish by Konopka, Prusik, \& Szulawski, 2020; and into Chinese by Winter, Webster, \& Cheung, 2008; as well as a 23-country sample in additional languages by Flores, Brown, \& Park, 2016). However, relatively 
little is known about the attitudes of Spanish-speakers toward the transgender population (FRA, 2014). Given that Spanish is the official language in 26 countries (with estimates that potential Spanish users in the world exceed 580 million) and that Latinxs constitute the largest ethnic minority group in the United States (also with estimates that in 2060, the United States will be the second largest Spanish-speaking country in the world, after Mexico), it is necessary to gain an accurate understanding of this population's attitudes toward transgender people (Fernández, 2019). Thus, in this study, we sought to translate an existing measure of transgender attitudes into Spanish and to assess its psychometric properties with a sample of Spanish speakers from Spain and the United States.

\section{Prejudice against transgender people within Spanish-speaking populations}

Although few in number, several studies have examined the attitudes of Spanish-speakers toward LGBTI individuals. For example, Arango and Arroyave (2017)conducted a qualitative study at three universities in Colombia in which participants reported perceptions of exclusion of transgender students and the absence of information and policies protecting transgender students on their campuses. In another study examining attitudes of social work students toward sexual diversity at the University of Mexico (Nuevo León), Rodriguez (2016) found the existence of sexist attitudes and a rejection of LGBTI people among the participants. In a similar study conducted in Puerto Rico, Esteban-Reyes, Ortiz-Mendoza, Rivera-Morales, Purcell-Baerga, and Ruiz-Mojica (2016) found that the sample of psychologists reported moderate levels of prejudice against transgender people in their community. In another study comparing student attitudes toward transgender people by major at a public university in Spain, it was found that students from the humanities and social sciences, especially from psychology, showed more positive attitudes toward transgender people compared to other majors (Ozamiz-Etxebarria, Picaza, Jiménez-Etxebarria, \& Cornelius-White, 2020). At the same time, the same study found that, overall, knowledge concerning transgender identity was low in the university environment. The results of a survey of 1,005 people residing in Spain also reported that $48 \%$ of the participants felt discrimination against transgender people was widespread in their country (Eurobarometer. Special Eurobarometer no 493, 2019). Additionally, in the same survey, almost 3 out of 10 reported that a transgender person would have fewer opportunities to apply for a job. Collectively, these studies suggest that there is an overall negative attitude toward transgender identified people among Spanish-speakers in Latin America and Spain. Moreover, similar to studies with English speakers, more negative attitudes toward transgender people have been found among males as compared to females within Spanish-speaking populations (Carrera-Fernandez, Lameiras-Fernandez, 
Rodriguez-Castro, \& Vallejo-Medina, 2014; Elischberger, Glazier, Hill, \& Verduzco-Baker, 2016; García-Barba, Serrano-Moragón, CamañesMartorell, Ruiz-Palomino, \& Ballester-Arnal, 2018; Landén \& Innala, 2000; Rodríguez \& Treviño, 2016).

Several studies of Spanish-speakers have also shown that those with a religious orientation tend to hold less accepting attitudes toward transgender individuals. For example, a recent study found a positive correlation between higher attendance at religious services and levels of prejudice toward transgender people in a sample of 233 psychologists and graduate students of psychology in Puerto Rico (Francia-Martínez, Esteban, \& Lespier, 2017). According to Alaminos and Del Pino (2017), factors such as regular church attendance and a defense of the traditional family model have been found to relate to higher levels of rejection of transgender people. Paralleling these trends, in a 2010 survey of over 1,100 Latinx LGBTI people across the United States, a little over one-third (35\%) of the participants reported being closeted in their religious communities (Pastrana, Battle, \& Harris, 2017). In fact, Worthen (2018) notes the particular relevance of religiosity in the study of transgender prejudice in Latino communities, linking religiosity to a sexist, patriarchal, and hyper-masculinized identity. This suggests the importance of a religiously nuanced assessment and understanding of transgender prejudice in this Spanish-speaking subpopulation.

\section{Discrimination, violence, and health consequences for transgender people within Spanish-speaking populations}

Transgender people suffer not only as victims of gender identity-based prejudice, but also as victims of overt discrimination and violence across multiple domains of life. For example, the Transgender Murder Monitoring project (Balzer, LaGata, \& Berredo, 2016) has systematically tracked murders throughout the world, and found that countries in Central and South America are some of the most lethal for transgender people in the world. Likewise, although the 29 Yogyakarta principles (Yogyakarta, 2007) —an application of the international human rights law to sexual orientation and gender identity-marked a milestone, the document notes that human rights violations based on these categories represent a global pattern. Moreover, these violations have been documented to be accompanied by hatred, discrimination, and exclusion in all areas of life (FRA, 2014; Gavilán, 2015; Lombardi, Wilchins, Priesing, \& Malouf, 2001; Pichardo \& Puche, 2019; Yogyakarta, 2007). As a case in point, in a review of studies on prejudice against sexual minorities in Costa Rica, Villaplana (2018) found rampant discrimination against those who do not conform to conventional sexual and gender norms in school communities. In the United States, Spanish-speaking transgender persons have also suffered discrimination along with other Americans who 
identify as transgender, but additionally bearing the intersectional stigma of their double minority status as Latino and transgender (Harrison-Quintana, Perez, \& Grant, 2012). In Spain, the Spanish National Health System (SIS) lacks data on gender identity in its statistical studies, which has contributed to the paucity of health interventions appropriate for transgender patients (GilBorrelli, Velasco, Martí-Pastor, \& Latasa, 2018). There is also evidence to suggest that LGBTI women experience greater levels of discrimination and violence compared to their male counterparts (García et al., 2019). For example, in previous studies, LGBTI women have reported their experiences that LGBTI spaces are more friendly to men than to women (Cárdenas, Barrientos, Gómez, \& Frías-Navarro, 2012; Corlouer, 2013).

Additionally, transgender people have consistently reported worse health status than the general population (Westwood et al., 2020), and the social inequalities they face have been shown to have implications for overall quality of life, affecting both mental and physical health (Chae \& Ayala, 2010; Dilley, Simmons, Boysun, Pizacani, \& Stark, 2010; Logan et al., 2019). Research has shown that discrimination is associated with poorer health, greater depression, and lower life satisfaction (Leahy \& Chopik, 2020). The minority stress model further suggests that stigma, prejudice, and discrimination create a hostile and stressful social environment giving rise to mental health challenges related to depressive symptoms and low self-esteem among minorities. This depressive and anxious symptomatology has been demonstrated to be more prevalent in sexual and gender minorities; and within the LGBTI group, it has been found to be even greater in transgender people than in others within the collective (Borgogna, McDermott, Aita, \& Kridel, 2018; Carroll, 2015; García et al., 2019; Marchueta, 2014). Notably, in a recent study, Yamanis et al. (2018) found that Latina transgender women in the United States suffer from significantly higher rates of depression compared to their African American or Asian counterparts. Research has also shown that LGBTI groups are at a higher risk of suicidal ideation and behavior compared to their heterosexual and cisgender counterparts (Tomicic et al., 2016).

As can be seen from above, there is a clear need to address the distressing situation faced by transgender individuals within Spanish-speaking populations. We suggest that in order to improve the quality of life of this population, it is necessary to first gain an accurate understanding of the prejudice that exists against transgender people and factors that may contribute to such prejudice so that policies and programs can be developed to decrease the stigmatization and discrimination experienced by transgender people. Thus, valid and reliable evaluation tools are needed as a first step to accomplish these goals. 


\section{Measuring attitudes toward transgender people}

In the last decade and a half, efforts have been made, particularly within English-speaking populations, to develop measures to assess attitudes toward transgender people. For example, Walch, Ngamake, Francisco, Stitt, and Shingler (2012) developed the Attitudes Toward Transgender Individuals Scale (ATTI) - a 20-item, one-dimensional transgender prejudice measurewhich was validated with a university student sample. While the relative brevity of the scale has been attractive to many, the ATTI has been criticized for its questionable content validity and factor structure (Morrison et al., 2017).

Another widely used measure of transphobia is the two-factor, 32-item Genderism and Transphobia Scale (GTS; Hill \& Willoughby, 2005), which was also originally validated with a university student sample. Although it is one of the most widely used transgender attitudes measures, the GTS has also been criticized for its questionable content and criterion-related validity and for its lack of stable factor structure across different samples, contributing to challenges in study replicability (Carrera-Fernandez et al., 2014; Morrison et al., 2017; Winter et al., 2008). The GTS has since been modified and translated into Spanish (SGTS-SF; Carrera-Fernandez et al., 2014), and the Spanish short version is a 12 -item, two-factor scale, measuring gender bashing and genderism/transphobia. Although an improvement from the original English GTS, one of its limitations is that while it was normed with a probabilistic sample, the sample was not representative of a larger part of Spain or Spanish-speakers outside of Spain (Carrera-Fernandez et al., 2014). Additionally, the seventh item on the scale ("God made two sexes and two sexes only") is a doublebarreled question, touching upon more than one issue, making it a poor item. While a complete review of other measures is beyond the scope of this paper, the reader may be interested in Morrison, Bishop, and Morrison (2018) review of a number of additional instruments.

In our study, we chose to translate and validate the Transgender Attitudes and Beliefs Scale (TABS; Kanamori et al., 2017), because of its several advantages over the aforementioned scales. First, unlike the development studies of the ATTI and the GTS, the TABS development study utilized a sample that did not consist exclusively of university students. Second, in keeping with the existing theoretical literature, TABS was developed as a multi-factor instrument (consisting of the interpersonal comfort dimension, sex/gender beliefs dimension, and human value dimension) to reflect the complex nature of attitudes and to capture religiously nuanced attitudes, not seen in previous measures. Although some criticisms exist, particularly regarding the oversampling of Christians in the TABS development study to test its ability to 
capture religiously nuanced attitudes (Billard, 2018; Morrison et al., 2017), this unique feature of TABS may actually be of value, especially in the Latinx context, as noted by Worthen (2018) (see above).

\section{Current study}

In light of ongoing prejudice and discrimination experienced by transgender individuals and the relative scarcity of research on Spanish-speakers' attitudes toward this population due to the lack of appropriate Spanish instruments (Garcia-Barba, et al., 2018), the purpose of this study was to translate the Transgender Attitudes and Beliefs Scale (TABS; Kanamori et al., 2017) into Spanish and to evaluate its psychometric properties. We utilized an international Spanish-speaking sample from Spain and the United States in order to attain a measure usable across Spanish-speaking subgroups. To assess the psychometric properties of the TABS-S, we examined its factor structure, calculated an estimate of the reliability of scores for each subscale and total scale, assessed item homogeneity by examining the corrected item-total correlation of all scale items, and garnered preliminary evidence for external (i.e., convergent and discriminant) and known-groups (i.e., gender difference) validity.

\section{Method}

\section{Procedures}

\section{Instrument translation}

Following the procedures recommended by Beaton, Bombardier, Guillemin, and Ferraz (2000), we translated the Transgender Attitudes and Beliefs Scale (TABS; Kanamori et al., 2017) into Spanish, using the back-translation methodology. First, an expert translator (a native Spanish-speaker of Spanish descent) translated the original instrument (including the instructions) into Spanish. Then, a second translator (a native Spanish-speaker of Spanish descent with English fluency) translated the Spanish translation back into English. Then, a third researcher (a native English-speaker) compared the original English instrument with the back-translated version to determine if they were equivalent. Minor revisions were made to the Spanish instrument after discussing apparent discrepancies between items on the original instrument and those on the back-translated instrument. Throughout the process, care was taken to retain construct meaning while being sensitive to cultural nuances and understanding for Spanish-speakers. While it is not uncommon during instrument translation for words and even concepts to be modified to 
attain equivalency in meaning (Brislin, Lonner, \& Thorndike, 1973), we chose to keep all items intact so that cross-cultural comparisons can be made with works using the original English version of TABS.

\section{Instrument validation}

After gaining IRB approval, we recruited Spanish-speaking U.S. adult participants (18 years of age or older) via Amazon Mechanical Turk (MTurk). MTurk is a 15 year old service that has been widely utilized by a growing number of social scientists and researchers. In comparison to traditional internet and college samples, MTurk has been shown to provide equal or better-quality samples, representing diverse populations across multiple demographic dimensions (Buhrmester, Kwang, \& Gosling, 2011; Ross, Irani, Silberman, Zaldivar, \& Tomlinson, 2010). In the current study, potential participants were first presented with a brief description of the study in MTurk. After indicating informed consent, participants were directed to Qualtrics, where they completed a brief demographics questionnaire (with items related to their sex, age, race, education, etc.), followed by the three main measures of the study, which were presented in a random order to minimize order effects. The "Prevent Ballot Box Stuffing" option was activated in Qualtrics to prevent participants from taking the survey more than once, and three attention check items were included to safeguard against careless respondents.

After gaining approval from the University's Ethics Board, participants from Spain were recruited from a pool of Social Education degree and Primary Education degree students at a public university in northern Spain. The researchers recruited students in their classes and asked for volunteers to participate in this study. Students who showed interest in the study were sent the link to the Google forms with the questionnaire items through the Moodle virtual platform used by the university. All students participated on a voluntary basis, received information about the procedure of the study, and gave their consent before participating in the study.

\section{Participants}

Data from a nonrandom sample of 605 participants were analyzed in the present study. The sample consisted of $40.0 \%$ males and $56.7 \%$ females (3.3\% missing data) with an average age of 35.84 years $(S D=9.63$ years). Approximately $38 \%$ of the sample was from the United States and $62 \%$ from Spain. The U.S. sample was majority White (61.0\%) and educated (53.2\% holding at least a Bachelor's degree). Due to limited diversity, racial information on participants was not collected in the Spanish sample. 


\section{Measures}

For the current study, two measures of transgender attitudes and one measure of self-esteem were utilized.

\section{Transgender Attitudes and Beliefs Scale-Spanish version}

The Transgender Attitudes Beliefs Scale (TABS; Kanamori et al., 2017) is a 29-item scale designed to assess attitudes toward transgender persons along the dimensions of interpersonal comfort, sex/gender beliefs, and human value. Items are rated on a 7 -point Likert scale, ranging from $1=$ strongly disagree to 7 = strongly agree, with higher scores indicating more positive attitudes toward transgender persons. Sample items include: "I would feel comfortable having a transgender person into my home for a meal" (interpersonal comfort subscale); "If you are born male, nothing you do will change that" (sex/gender beliefs subscale); and "Transgender individuals should be treated with the same respect and dignity as any other person" (human value subscale). The internal consistency of TABS scores reported in the original scale development study with an online U. S. sample was high for all subscales and the overall scale (interpersonal comfort $\alpha=.97$; gender beliefs $\alpha=.95$; human value $\alpha=.93$; overall scale $\alpha=.98)$. Kanamori et al. (2017) also reported evidence of construct validity in the forms of convergent and discriminant validity. The Spanish translation of TABS (TABS-S) was used in this study.

\section{Spanish Genderism and Transphobia Scale short form}

The original Genderism and Transphobia Scale (GTS; Hill \& Willoughby, 2005) is a 32-item scale, assessing negative attitudes toward transgender individuals (defined broadly to include transsexuals, transgenderists, and transvestites), along the dimensions of transphobia (attitudinal component), genderism (cognitive component), and gender bashing (behavioral component). The Spanish Genderism and Transphobia Scale Short Form (SGTS-SF; Carrera-Fernandez et al., 2014) is a modified Spanish translation of the GTS, consisting of 12 items, tapping into gender bashing and transphobia/genderism. Items on the SGTS-SF are rated on a 7-point Likert scale, ranging from 1 = strongly agree/muy de acuerdo to 7 = strongly disagree/muy en desacuerdo. Higher scores indicate more accepting attitudes toward transgender individuals. Sample items on the SGTS-SF include: "I have beat up men who act like sissies" (gender bashing subscale) and "God made two sexes and two sexes only" (transphobia/genderism subscale). In the present study, the response scale was reverse coded for ease of interpretation. Carrera-Fernandez et al. (2014) reported evidence for the construct validity and the internal reliability 
of SGTS-SF scores in a sample of Spanish adolescents (gender bashing $\alpha=.80$ and transphobia/genderism $\alpha=.83$ ). This scale was included to assess the convergent validity of the TABS-S.

\section{Spanish Rosenberg Self-Esteem Scale}

The Spanish Rosenberg Self-Esteem Scale (SRSES; Martin-Albo, Núñez, Navarro, \& Grijalvo, 2007) is a 10-item scale originally developed by Rosenberg (1989) and used to measure global self-esteem. Responses to items on the SRSES are rated on a 4-point Likert scale, ranging from $1=$ totally disagree to $4=$ totally agree, with higher scores representing greater selfesteem. Sample items on the SRSES include "Soy capaz de hacer las cosas tan bien como la mayoría de las personas" ("I am able to do things as well as most other people") and "A veces me siento realmente inútil" ("I certainly feel useless at times"). The scale development study reported a high internal consistency of SRSES scores ( $\alpha=.85$ in the first administration and $\alpha=.88$ in the second administration) as well as a high test-retest correlation $(r=.84)$. Construct validity was demonstrated in the same study by a significant positive correlation between self-esteem and the five self-concept dimensions of the scale $(r=.28-.50)$. This scale was included to assess the discriminant validity of the TABS-S.

\section{Analytical methods}

Confirmatory Factor Analysis (CFA) was used to assess the dimensionality of the TABS-S with a Spanish-speaking sample, using the robust SatorraBentler (MLM) estimation method in Mplus version 7.4 (Muthén \& Muthén, 2015). The model chi-square test along with three other fit indices-comparative fit index (CFI), root-mean-square error of approximation (RMSEA), and standardized root-mean-square residual (SRMR) were used to evaluate the data-model fit. The criteria used for evaluation were: CFI greater than or equal to .90 and RMSEA and SRMR less than .08 (Kline, 2016). SPSS version 25 was then used to examine other psychometric properties of the TABS-S. An estimate of the internal reliability of scores was examined by calculating Cronbach's alpha values on the three subscales and the overall scale. We additionally examined the alpha-if-deleted values and the corrected item-total correlation for all items on the subscales. Convergent and discriminant validity of the TABS-S was assessed by examining the correlations of its scores with the SGTS-SF and SRSES. Finally, a one-way MANOVA was conducted to test gender differences on the three subscales of the TABS-S as a measure of known-groups validity. 


\section{Results}

\section{Data preparation and preliminary analysis}

We first inspected the data for completeness and accuracy of input. Participants who failed to meet the requirements to participate in the study and were missing more than $50 \%$ of the survey responses (including those who failed to pass any of the attention checks) were omitted, which reduced the pool of participants from 740 to 605 . We then conducted a missing data analysis, which indicated that the remaining data were not missing completely at random (Little's MCAR test: $\chi^{2}=$ $223.58, d f=99, p<.001)$. Since less than $5 \%$ of the overall data were missing and the majority of data missing was on a demographic variable (i.e., 20 cases missing information on sex, 3 cases on response to SGTS-SF Q2.6, and one case on response to SGTS-SF Q2.3-2.5), we used pairwise exclusion to exclude cases with missing values on relevant analyses. Thus, the final sample size for the study was 605 .

We then screened the data to ensure that key assumptions for Confirmatory Factor Analysis (CFA)-adequate sample size, lack of multicollinearity and outliers, and univariate and multivariate normality-were met. The sample size was adequate, and there was no evidence of multicollinearity (Tolerance $>$ .1 VIF $<10$ ). The data was not screened for outliers because items on the survey measured a construct that was not expected to be normally distributed and may illicit strong responses (i.e., attitudes toward transgender individuals), which could result in the presence of outliers. Thus, we instead screened the data for validity of values (e.g., random response patterns), and the data were deemed to be free of invalid values. As expected, the data failed to meet the assumptions of univariate and multivariate normality $(p<.001)$, likely due to the large sample size $(N=605)$ and the nature of the constructs assessed as previously noted. Given the non-normal nature of the data, we used the robust Satorra-Bentler (MLM) estimation method in conducting the CFA.

\section{Confirmatory Factor Analysis (CFA)}

We conducted a Confirmatory Factor Analysis (CFA) to test the factor structure of the TABS-S. A three-factor measurement model, consistent with the original English version of TABS (Kanamori et al., 2017), was examined. The specified model consisted of three latent variables and 29 observed variables, where 14 indicators loaded on the first latent factor, Interpersonal Comfort; 10 indicators loaded on the second latent factor, Sex/Gender Beliefs; and 5 indicators loaded on the third latent factor, Human Value. Consistent with the original TABS model, no indicator cross-loadings were permitted and correlations among the three latent factors were estimated. Fit indices indicated data-model fit approaching adequate range: $\chi^{2}(374, n=605)=1406.17, p<.001$; $\mathrm{RMSEA}=0.068(90 \% \mathrm{CI}=0.064$; $0.071), \mathrm{CFI}=0.875, \mathrm{SRMR}=0.057$. An examination of the standardized factor 
loadings (.48-.92) and $\mathrm{R}^{2}$ values (.23-.85) suggested that the indicators sufficiently measured their respective latent factors (Hair, Black, Babin, \& Anderson, 2010; Hooper, Coughlan, \& Mullen, 2008). Thus, modification indices were examined to identify possible error term covariances to improve model fit. The error terms for T1.4 R and T1.3 R were permitted to correlate because error covariance was reasonably expected due to wording and conceptual similarity between the items. Error terms for T2.8 R and T2.5 R were also permitted to correlate for the same reason. The re-specified model with 3 latent factors, 29 indicators, 3 factor covariances, and 2 error term covariances yielded good model fit: $\chi^{2}(372, n=$ $605)=1178.76, p<.001$; RMSEA $=0.060(90 \% \mathrm{CI}=0.056 ; 0.064), \mathrm{CFI}=0.902$, $\mathrm{SRMR}=0.052$. Given the large sample size, we calculated a normed chi-square, which yielded a value less than 4 (normed $\chi^{2}=3.17$ ), indicating adequate model fit. All factor loadings were significant and moderate to high, suggesting that the items sufficiently measured the purported latent variables (see Figure 1 for final CFA model with standardized parameter estimates). The factor correlations of the three subscales were also in a similar range with and followed the same pattern as those found in the original TABS: Interpersonal Comfort and Sex/Gender Beliefs, $r=.86$ (original TABS, $r=.85$ ); Interpersonal Comfort and Human Value, $r=.69$ (Original TABS, $r=.77$ ); Sex/Gender Beliefs and Human Value, $r=.58$ (Original TABS, $r=.62$ ). The means and standard deviations of the factor scores for each of the subscales and the total scale are found in Table 1.

Notes. $1 . N=605$. 2. All parameter estimates were significant at $p \leq .001$.

\section{Internal consistency}

An estimate of one measure of the internal consistency of the TABS-S scores was examined by calculating Cronbach's alpha for each of the subscales and for the scale as a whole. As shown in Table 1, results supported good reliability of scores for the subscales and the total scale. Likewise, the corrected item-total correlation for all items was above .45, indicating item homogeneity, and an examination of the alpha-if-deleted values suggested that the deletion of items would not improve the Cronbach's alpha for the corresponding subscales, which provided further support for the reliability of TABS-S scores.

Table 1. Mean, standard deviation, and Cronbach's alpha of subscales and total scale.

\begin{tabular}{lccc}
\hline Subscale & $M$ & $S D$ & $a$ \\
\hline Interpersonal Comfort $^{\text {a }}$ & 82.8 & 17.41 & 0.94 \\
Sex/Gender Belief $^{\text {b }}$ & 54.64 & 14.87 & 0.92 \\
Human Value $^{c}$ & 32.6 & 4.49 & 0.87 \\
Total & 170.04 & 33.47 & 0.96 \\
\hline
\end{tabular}

Note. $M=$ mean; $S D=$ standard deviation; $a=$ Cronbach's alpha.

${ }^{\mathrm{a}}$ Absolute range $=14-98$.

${ }^{\mathrm{b}}$ Absolute rage $=10-70$.

'Absolute range $=5-35$.

${ }^{\mathrm{d}}$ Absolute range $=29-203$. 


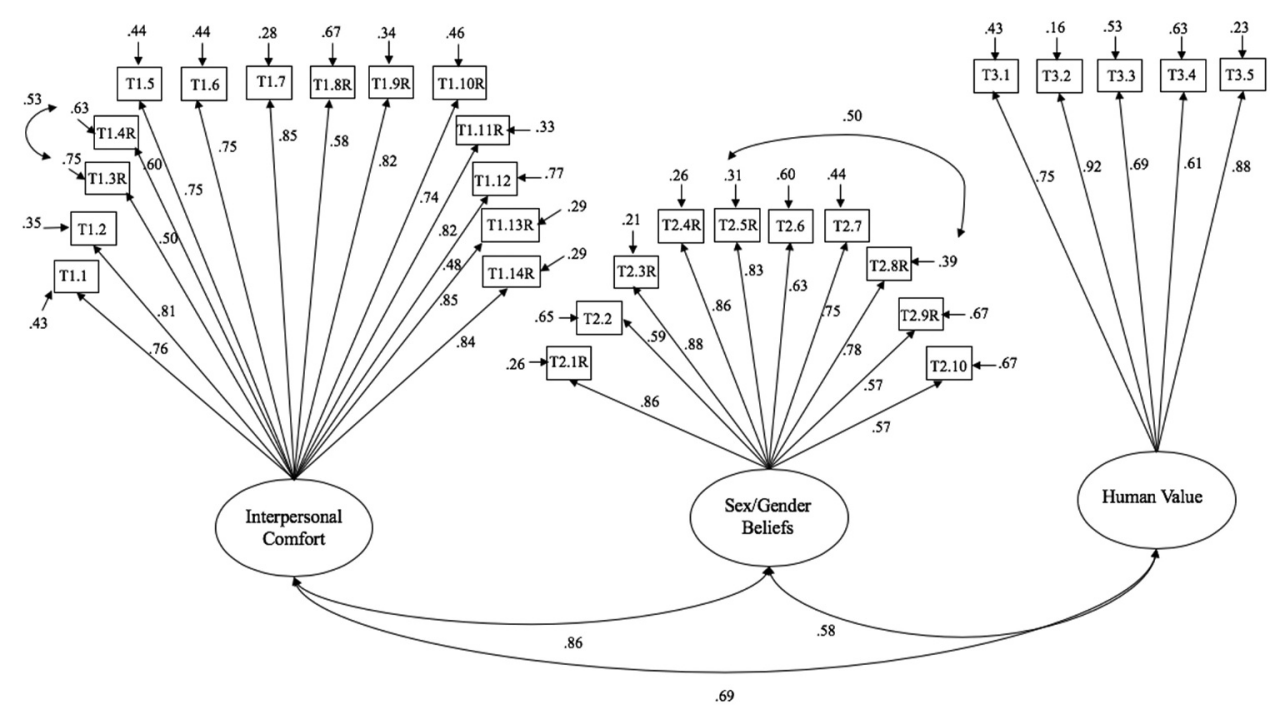

Figure 1.

\section{Convergent and discriminant validity}

To evaluate the external validity of the TABS-S, we examined Pearson's correlation coefficients between TABS and two scales-one measuring a similar construct (SGTS-SF) and another measuring a theoretically unrelated construct (SRSES). Because higher scores on TABS indicate more accepting attitudes toward transgender persons while higher scores on the SGTS-SF indicate more negative attitudes toward transgender persons, we expected a strong negative correlation between TABS and SGTS-SF. Results showed a significant and strong correlation in the expected direction between TABS and SGTS-SF ( $r$ $(603)=-.89, p<.001)$, providing initial evidence for the convergent validity of the TABS-S scores. On the other hand, since TABS and SRSES measure theoretically unrelated constructs, we expected no significant correlation between the two scales. As expected, the correlation between the scores on the TABS-S and SRSES were statistically non-significant $(r(603)=.004, p=.913)$, thus demonstrating initial evidence of the discriminant validity of TABS-S scores.

\section{Gender differences}

To garner evidence of known-groups validity of the TABS-S, we examined gender differences in TABS-S scores in our sample. Known-groups validity refers to the ability of a measure to capture differences between groups that theory or empirical data predicts will be different on the underlying construct (Bandalos, 2018). Given the consistent finding in previous research that males tend to exhibit more negative attitudes toward transgender persons than their female counterparts (e.g., Acker, 2017; Hill \& Willoughby, 2005; Norton \& 
Herek, 2013; Tebbe \& Moradi, 2012), we examined the mean differences between males and females on the subscales of the TABS-S as a measure of known-groups validity. Results showed that there were statistically significant gender differences on attitudes toward transgender persons: $F(3,581)=30.68$, $p<.001$; Wilk's lambda $=.86, \eta_{\mathrm{p}}{ }^{2}=.14$. Specifically, there was a gender difference on all three subscales of TABS: Interpersonal Comfort $F(1,583)=$ 84. 73, $p<.001, \eta_{\mathrm{p}}{ }^{2}=.13$; Sex/Gender Beliefs $F(1,583)=77.57, p<.001, \eta_{\mathrm{p}}{ }^{2}=$ .12 ; Human Value $F(1,583)=32.23, p<.001, \eta_{\mathrm{p}}{ }^{2}=.05$. An examination of the means supports previous research in that females demonstrated more favorable attitudes toward transgender persons on all three subscales of TABS (see Table 2 for means and standard deviations of subscales by gender).

\section{Discussion, limitations, and future directions}

The purpose of this study was to translate and validate a Spanish version of the Transgender Attitudes and Beliefs Scale (TABS; Kanamori et al., 2017). The Transgender Attitudes and Beliefs Scale-Spanish (TABS-S) version was first created by translating the original TABS into Spanish, using the back-translation method (Beaton et al., 2000), while keeping the original items intact so that the translated instrument may be used in cross-cultural comparison studies.

As one evidence of construct validity, Confirmatory Factor Analysis (CFA) was conducted to analyze the factor structure of TABS-S. Results confirmed the three-factor structure originally proposed and found in the English TABS, providing evidence for the dimensional stability of the measured construct. This contrasts with the GTS (Hill \& Willoughby, 2005), which has failed to demonstrate factor stability across diverse samples (Carrera-Fernandez et al., 2014; Morrison et al., 2017; Winter et al., 2008), making the TABS-S a promising tool in advancing cross-cultural studies related to transgender prejudice. Moreover, given the relevance of religious beliefs in the understanding of transgender prejudice among Latinxs (Worthen, 2018), TABS-S, with its sensitivity to religiously rooted beliefs and attitudes, may be particularly useful in the assessment of transgender prejudice among religiously oriented Spanish-speaking subpopulations.

Table 2. Means and standard deviations of subscales by gender.

\begin{tabular}{lcc}
\hline & \multicolumn{2}{c}{ Gender } \\
\cline { 2 - 3 } Subscale & Male & Female \\
\hline Interpersonal Comfort & $75.14(19.93)$ & $87.85(13.49)$ \\
Sex/Gender Beliefs & $48.33(15.61)$ & $58.78(12.98)$ \\
Human Value & $31.31(5.35)$ & $33.42(3.64)$ \\
\hline
\end{tabular}


Initial evidence of the construct validity of TABS-S was further demonstrated by a significant and strong correlation of its scores to those on the SGTS-SF (assessing transphobia) and a non-significant correlation to those on SRSES (measuring self-esteem), which replicates findings from the original TABS development study (Kanamori et al., 2017). Likewise, consistent with previous research (e.g., Acker, 2017; Norton \& Herek, 2013; Tebbe \& Moradi, 2012), our study found that males held more negative attitudes toward transgender persons than their female counterparts, providing evidence for knowngroups validity. As previously articulated in the literature, this gender difference may be explained in part by a strong commitment to traditional gender roles found in males (as compared to females), who may, therefore, find transgender people threatening to the conventional gender binary they seek to uphold (e.g., Carrera-Fernandez et al., 2014; Norton \& Herek, 2013). The mean scores on TABS-S subscales by gender also largely paralleled those reported in the original TABS study (Kanamori et al., 2017), though the scores were slightly higher in the Spanish-speaking sample. At the same time, this study did not evaluate TABS-S' responsiveness/sensitivity to detecting attitudinal changes as a result of interventions expected to impact the target construct as has been demonstrated in the original version in English (Picaza, Ozamiz-Etxebarria, Jimenez-Extebarria, \& Cornelius-White, 2020; Thompson, 2019). Thus, studies conducting interventions designed to change attitudes toward transgender people using TABS-S as a measure of transgender prejudice should be conducted both to identify what works to reduce prejudice and to establish an additional measure of external validity of TABS-S scores (Messick, 1995).

In terms of the reliability of TABS-S scores, the Cronbach's alphas for the subscales and the total scale along with the corrected item-total correlations of the scale items demonstrated adequate internal consistency of scores and high item homogeneity (Nunnally \& Bernstein, 1994). The internal consistency of TABS-S scores was also consonant with those reported in the original TABS development study and another study utilizing TABS (Kanamori et al., 2017; Kanamori, Pegors, Hall, \& Guerra, 2019). The present study, however, did not evaluate the test-retest reliability of TABS-S scores, which should be examined in future studies to provide further evidence of the reliability of its scores.

Additional limitations of the study relate to the study sample. According to the latest report from the Cervantes Institute (Fernández, 2019), Spanish is the second most frequently spoken language with nearly 580 million speakers across 26 countries. This study included samples from the second largest (Spain) and fifth largest (U.S.) concentrations representing both Europe and the Americas. At the same time, the cultural differences among these 26 countries are vast; thus, additional validity evidence to evaluate the appropriateness of its use in other Spanish-speaking populations should be garnered, particularly from Central or Latin American countries, and indeed ideally even 
from within additional samples in Spain and the United States. Moreover, the self-selection of participants from an online platform and a university setting likely excluded those from underrepresented communities, including older adults and low-income individuals who may lack access to the internet and who are not connected to a university. Future studies, therefore, should be conducted with more heterogeneous and non-online samples.

\section{Conclusions}

In summary, there is preliminary evidence to suggest that TABS-S is a reliable and valid instrument appropriate for use to assess transgender prejudice among Spanish-speaking populations. At the same time, because test validation is best conceptualized as "a program of research in which one attempts to obtain a body of evidence that, taken as a whole, would support the intended uses of and inferences from the test scores" (Bandalos, 2018, p. 263), further studies should be conducted to continue to build the necessary body of evidence to support the psychometric strength of TABS-S.

In terms of applied research, the TABS-S may have wide utility in various settings with Spanish-speakers, such as in education and healthcare (both mental health and physical health), to assess attitudes toward transgender persons. More specifically, the TABS-S may be used as a pre/post assessment of prejudice reduction trainings to evaluate the effectiveness of such trainings in reducing transgender prejudice among professionals who work with transgender clients. Given that prejudice and discrimination against transgender individuals are not uncommon even among helping professionals (e.g., Esteban-Reyes et al., 2016), tools to assess baseline levels of prejudice and to evaluate the effectiveness of interventions are of value. Likewise, TABS-S may be a useful and appropriate tool in evaluating campus climate surrounding transgender students in Spanish-speaking educational settings to help combat the discrimination they face on college campuses (e.g., Arango \& Arroyave, 2017; Rodriguez, 2016; Villaplana, 2018). Such research may lead to improvements in the quality of life of this population through policies and programs developed to decrease the stigmatization and discrimination experienced by transgender people.

\section{Acknowledgment}

The authors would like to thank Julie A. Baumann for her assistance with this article.

\section{Disclosure statement}

No potential conflict of interest was reported by the author(s). 


\section{Funding}

The author(s) reported there is no funding associated with the work featured in this article.

\section{ORCID}

Yasuko Kanamori (D) http://orcid.org/0000-0003-3597-2224

Eneritz Jiménez-Etxebarria (D) http://orcid.org/0000-0003-1473-7778

Jeffrey H. D. Cornelius-White (D) http://orcid.org/0000-0003-1994-6827

Naiara Ozamiz-Etxebarria (D) http://orcid.org/0000-0003-4594-1480

Kelly N. Wynne (D) http://orcid.org/0000-0002-3665-4458

Maitane Picaza Gorrotxategi (D) http://orcid.org/0000-0001-5419-8356

\section{Data availability statement}

The data that support the findings of this study are available from the corresponding author, Jeffrey Cornelius-White, upon reasonable request.jcornelius-white@Missouristate.edu.

\section{References}

Acker, G. M. (2017). Transphobia among students majoring in the helping professions. Journal of Homosexuality, 64(14), 2011-2019. doi:10.1080/00918369.2017.1293404.

Alaminos, M. P., \& Del Pino, E. (2017). Actitudes hacia la transexualidad en la universidad. Un estudio con estudiantes del grado de pedagogía. In A. R. Fernández, and R. Ravina (Eds.), Sexualidades diversas interferencias entre el arte, la educación y la sociedad (pp. 111-130). Universidad Metropolitana.

Arango, M. A., \& Arroyave, O. (2017). Prácticas de exclusión de personas transgénero en ámbitos universitarios colombianos. Revista de Psicología, 9(2), 47-66. doi:10.17533/udea. rp.v9n2a04.

Balzer, C., LaGata, C., \& Berredo, L. (2016). TMM anual report 2016. TVT Publication Series, 14. Transgender Europe (www.TGEU.org). Retrieved April 4, 2020, from https://transre spect.org/wp-content/uploads/2016/11/TvT-PS-Vol14-2016.pdf

Bandalos, D. L. (2018). Measurement theory and applications for the social sciences. Guilford Press.

Beaton, D. E., Bombardier, C., Guillemin, F., \& Ferraz, M. B. (2000). Guidelines for the process of cross-cultural adaptation of self-report measures. Spine, 25(4), 3186-3191 .

Billard, T. J. (2018). Attitudes toward transgender men and women: Development and validation of a new measure. Frontiers and Psychology, 9, 387. doi:10.3389/fpsyg.2018.00387.

Borgogna, N. C., McDermott, R. C., Aita, S., \& Kridel, M. M. (2018). Anxiety and depression across gender and sexual minorities: Implications for transgender, gender nonconforming, pansexual, demisexual, asexual, queer, and questioning individuals. Psychology of Sexual Orientation and Gender Diversity, 6(1), 54-63. doi:10.1037/sgd0000306.

Brislin, R. W., Lonner, W. J., \& Thorndike, R. M. (1973). Cross-cultural research methods. Wiley.

Buhrmester, M., Kwang, T., \& Gosling, S. D. (2011). Amazon's Mechanical Turk: A new source of inexpensive, yet high-quality, data? Perspectives on Psychological Science, 6(1), 3-5. doi:10.1177/1745691610393980. 
Cárdenas, M., Barrientos, J., Gómez, F., \& Frías-Navarro, D. (2012). Attitudes toward lesbians and gay men and their relationship with sex role in a sample of Chilean university students. International Journal of Sexual Health, 24, 226-236. doi:10.1080/19317611.2012.700687.

Carrera-Fernandez, M., Lameiras-Fernandez, M., Rodriguez-Castro, Y., \& Vallejo-Medina, P. (2014). Spanish adolescents' attitudes toward transpeople: Proposal and validation of a short form of the Genderism and Transphobia Scale. The Journal of Sex Research, 51(6), 654-666. doi:10.1080/00224499.2013.773577.

Carroll, J. (2015). Sexuality now: Embracing diversity (5th ed.). Cengage Learning.

Chae, D. H., \& Ayala, G. (2010). Sexual orientation and sexual behavior among Latino and Asian Americans: Implications for unfair treatment and psychological distress. Journal of Sex Research, 47(5), 451-459. doi:10.1080/002224490903100579.

Corlouer, M. (2013). Quelle places pour lesbiennes? In A. Alessandrin \& Y. Ribaud (Eds.), Geographie des homphobies. Editions Armand Colin.

Dilley, J. A., Simmons, K. W., Boysun, M. J., Pizacani, B. A., \& Stark, M. J. (2010). Demonstrating the importance and feasibility of including sexual orientation in public health surveys: Health disparities in the Pacific Northwest. American Journal of Public Health, 100(3), 460-467. doi:10.2105/AJPH.2007.130336.

Elischberger, H., Glazier, J., Hill, E., \& Verduzco-Baker, L. (2016). Boys don't cry or do they? Adult attitudes toward and beliefs about transgender youth. Sex Roles, 75(5-6), 197-214. doi:10.1007/s11199-016-0609-y.

Esteban-Reyes, C., Ortiz-Mendoza, C., Rivera-Morales, N., Purcell-Baerga, P. L., \& RuizMojica, G. (2016). La educación del género en peligro de extinción: Preparacion de psicoterapeutas clínicos en Puerto Rico. Revista Puertoriqueña de psicología, 27(1), 80-93.

Eurobarometer. Special Eurobarometer $n^{\circ}$ 493. (2019). Discrimination in the European Union. Retrieved April 4, 2020, from file:///C:/Users/502434/Downloads/ebs_493_fact_es_en.pdf

Fernández, D. (2019). El Español: Una lengua viva. Informe 20119. Instituto Cervantes.

Flores, A. R., Brown, T. N. T., \& Park, A. S. (2016). Public support for transgender rights: A twenty-three country survey. The Williams Institute, Retrieved April 4, 2020, from https:// williamsinstitute.law.ucla.edu/wp-content/uploads/Public-Opinion-Trans-23-CountriesDec-2016.pdf

FRA. (2014). EU LGBT Survey-European Union Lesbian, Gay, Bisexual and Transgender Survey-Main Results. Luxembourg: Publications Office of the European Union. Retrieved June 25, 2019, from http://fra.europa.eu/en/publication/2014/eu-lgbt-survey-europeanunion-lesbian-gay-bisexual-and-transgender-survey-main

Francia-Martínez, M., Esteban, C., \& Lespier, Z. (2017). Actitudes, conocimiento y distancia social de psicoterapeutas con la comunidad transgénero y transexual. Revista puertorriqueña de psicología, 28(1), 98-113.

Garcia-Barba, M., Serrano Moragon, N., Camanes Martorell, J., Ruiz-Palomino, E., \& BallesterArnal, R. (2018). Actitudes hacia la transexualidad en jóvenes. Agora de salut, 5, 11-19. doi:10.6035/AgoraSalut.2018.5.1.

García, M., Martine, N., Giménez, C., Nebot, J. E., Ballester, R., \& Ruiz, E. (2019). Discriminación y actitudes hacia la diversidad afectivo-sexual: La experiencia de las mujeres. Dossiers Feministes, 25(25), 73-90. doi:10.6035/Dossiers.2019.25.6.

Gavilán, J. (2015). El sistema educativo y la transexualidad. In J. J. En Lleiva, V. M. Martín, E. S. Vila, \& J. E. Sierra (Eds.), Género, Educación y Convivencia. Dykinson.

Gil-Borrelli, C., Velasco, C., Martí-Pastor, M., \& Latasa, P. (2018). La identidad de género, factor de desigualdad olvidado en los sistemas de información de salud de España. Gaceta Sanitaria, 32(2), 184-186. doi:10.1016/j.gaceta.2017.10.004.

Hair, J. F., Black, W. C., Babin, B. J., \& Anderson, R. E. (2010). Multivariate data analysis (7th ed.). Pearson Prentice Hall. 
Harrison-Quintana, J., Perez, D., \& Grant, J. (2012). Injustice at every turn: A look at Latino/a respondents in the National Transgender Discrimination Survey. Retrieved April 4, 2020, from https://transequality.org/sites/default/files/docs/resources/ntds_latino_english_2.pdf

Hill, D., \& Willoughby, B. (2005). The development and validation of the genderism and transphobia scale. Sex Roles, 53(7-8), 531-544. doi:10.1007/s11199-005-7140-x.

Hooper, D., Coughlan, J., \& Mullen, M. (2008). Structural equation modeling: Guidelines for determining model fit. Electronic Journal of Business Research Methods, 6, 53-60.

Kanamori, Y., Cornelius-White, J. H. D., Pegors, T. K., Daniel, T., \& Hulgus, J. F. (2017). Development and validation of the Transgender Attitudes and Beliefs Scale (TABS). Archives of Sexual Behavior, 46(5), 1503-1515. doi:10.1007/s10508-016-0840-1.

Kanamori, Y., Pegors, T. K., Hall, J., \& Guerra, R. (2019). Christian religiosity and attitudes toward the human value of transgender individuals. Psychology of Sexual Orientation and Gender Diversity, 46(1), 42-53. doi:10.1037/sgd0000305.

Kline, R. (2016). Principles and practice of structural equation modeling (4th ed.). Guilford Press.

Konopka, K., Prusik, M., \& Szulawski, M. (2020). Two sexes, two genders only: Measuring attitudes toward transgender individuals in Poland. Sex Roles, 82(9-10), 600-621. doi:10.1007/s11199-019-01071-7.

Landén, M., \& Innala, S. (2000). Attitudes toward transsexualism in a Swedish national survey. Archives of Sexual Behavior, 29(4), 375-388. doi:10.1023/a:1001970521182.

Leahy, K. E., \& Chopik, W. J. (2020). The effect of social network size and composition on the link between discrimination and health among sexual minorities. Journal of Aging and Health. doi:10.1177/0898264320908982.

Logan, S., Reisner, S. L., Findling, M. G., Blendon, R. J., Benson, J. M., Sayde, J. M., \& Miller, C. (2019). Discrimination in the United States: Experiences of lesbian, gay, bisexual, transgender, and queer Americans. HSR Health Services Research, 54(S2), 1454-1466. doi:10.1111/ 1475-6773.13229.

Lombardi, E. L., Wilchins, R., Priesing, D., \& Malouf, D. (2001). Gender violence: Transgender experiences with violence and discrimination. Journal of Homosexuality, 42(1), 89-101. doi:10.1300/J082v42n01-05.

Marchueta, A. (2014). Consecuencias del bullying homofóbico retrospectivo y los factores psicosociales en el bienestar psicológico de sujetos LGB. Revista de Investigación Educativa, 32(1), 255-271.

Martin-Albo, J., Núñez, J., Navarro, J., \& Grijalvo, F. (2007). The Rosenberg Self-Esteem Scale: Translation and validation in university students. The Spanish Journal of Psychology, 10(2), 458-467. doi:10.1017/S1138741600006727.

Messick, S. (1995). Validity of psychological assessment: Validation of inferences from persons' responses and performances as scientific inquiry into score meaning. American Psychologist, 50(9), 741-749. doi:10.1037/0003-066X.50.9.741.

Morrison, M. A., Bishop, C. J., Gazzola, S. B., McCutcheon, J. M., Parker, K., \& Morrison, T. G. (2017). Systematic review of the psychometric properties of transphobia scales. International Journal of Transgenderism, 18(4), 395-410. doi:10.1080/15532739.2017.1332535.

Morrison, M. A., Bishop, C. J., \& Morrison, T. G. (2018). What is the best measure of discrimination against trans people?: A systematic review of the psychometric literature. Psychology \& Sexuality, 9(3), 269-287. doi:10.1080/19419899.2018.1484798.

Muthén, L. K., \& Muthén, B. O. (2015). Mplus user's guide (Seventh ed.). Muthén \& Muthén.

Norton, A., \& Herek, G. (2013). Heterosexuals' attitudes toward transgender people: Findings from a national probability sample of U.S. adults. Sex Roles, 68(11-12), 738-753. doi:10.1007/s11199-011-0110-6.

Nunnally, J. C., \& Bernstein, I. H. (1994). Psychometric theory (3rd ed.). McGraw-Hill. 
Ozamiz-Etxebarria, N., Picaza, M., Jiménez-Etxebarria, E., \& Cornelius-White, J. H. D. (2020). Measuring discrimination against transgender people at the University of the Basque Country and in a non-university sample in Spain. International Journal of Environmental Research and Public Health, 17(7), 2374. doi:10.3390/ijerph17072374.

Pastrana, A., Battle, J., \& Harris, A. (2017). An examination of Latinx LGTB populations across the United States. Palgrave.

Picaza, M., Ozamiz-Etxebarria, N., Jimenez-Extebarria, E., \& Cornelius-White, J. H. D. (2020). Improvement in gender and transgender knowledge in university students through the Creative Factory methodology. Frontiers in Psychology, 11, 367. Retrieved April 4, 2020, from https://www.frontiersin.org/articles/10.3389/fpsyg.2020.00367/full

Pichardo, J. I., \& Puche, L. (2019). Universidad y diversidad sexogeneìrica: Barreras, innovaciones y retos de futuro methaodos. Revista de Ciencias Sociales, 7, 10-26. doi:10.17502/m. rcs.v7i1.287.

Riggs, D. W., \& Sion, R. (2017). Gender differences in cisgender psychologists' and trainees' attitudes toward transgender people. Psychology of Men \& Masculinity, 18(2), 187-190. doi:10.1037/men0000047.

Rodríguez, L. M., \& Treviño, L. (2016). Sexism and attitudes towards sexual diversity in Mexican students of social work. Trabajo Social Global, 6(11), 3-30.

Rodriguez, L. M. (2016). Percepción sobre la violencia intragenero en una muestra de estudiantes de Trabajo Social. Documentos de Trabajo Social, 58, 80-94.

Rosenberg, M. (1989). Society and the adolescent self-image. Princeton University Press.

Ross, J., Irani, L., Silberman, M., Zaldivar, A., \& Tomlinson, B. (2010). Proceedings from CHI EA 2010: Who are the Crowdworkers?: Shifting demographics in Amazon Mechanical Turk. Atlanta, GA.

Tebbe, E. N., \& Moradi, B. (2012). Anti-transgender prejudice: A structural equation model of associated constructs. Journal of Counseling Psychology, 59(2), 251-261. doi:10.1037/ a0026990.

Thompson, J. A. (2019). Improving nursing students' attitudes and beliefs about transgender clients through the use of a simulated clinical experience [Doctor of Nursing Practice Projects]. George Washington University. Retrieved April 4, 2020, from https://hsrc.him melfarb.gwu.edu/son_dnp/45/

Tomicic, A., Gálvez, C., Quiroz, C., Martínez, C., Fontbona, J., Rodríguez, J., ... Lagazzi, I. (2016). Suicidio en poblaciones lesbiana, gay, bisexual y trans: Revisión sistemática de una década de investigación (2004-2014). Revista médica de Chile, 144(6), 723-733. doi:10.4067/ S0034-98872016000600006.

Villaplana, Á. C. (2018). Transexualidad y transfobia en el sistema educativo. Revista Humanidades, 8(1), 163-193.

Walch, S. E., Ngamake, S. T., Francisco, J., Stitt, R. L., \& Shingler, K. A. (2012). The attitudes toward transgendered individuals scale: Psychometric properties. Archives of Sexual Behavior, 41(5), 1283-1291. doi:10.1007/s10508-012-9995-6.

Westwood, S., Willis, P., Fish, J., Hafford-Letchfield, T., Semlyen, J., King, A., ... Becares, L. (2020). Older LGTB + health inequalities in the UK: Setting a research agenda. Epidemiology and Community Health, 74(5), 408-411. doi:10.1136/jech-2019-213068.

Winter, S., Webster, B., \& Cheung, P. K. (2008). Measuring Hong Kong undergraduate students' attitudes towards transpeople. Sex Roles, 59(9), 670-683. doi:10.1007/s11199008-9462-y.

Worthen, M. (2018). "Gay Equals White”? Racial, ethnic, and sexual identities and attitudes toward LGBT individuals among college students at a Bible Belt university. The Journal of Sex Research, 55(8), 995-1011. doi:10.1080/00224499.2017.1378309. 
Yamanis, T., Malik, M., Río, A. M., Wirtz, A., Cooney, E., Lujan, M., ... Poteat, T. (2018). Legan immigration status is associated with depressive symptoms among Latina transgender women in Washington, DC. Environmental Research and Public Health, 15, 1246. doi:10.3390/ijerph15061246.

Yogyakarta, P. (2007). Principios sobre la aplicación de la legislación internacional de derechos humanos en relación con la orientación sexual y la identidad de género. Yogyakarta, Indonesia: Comisión Internacional de Juristas y Servicio Internacional para los Derechos Humanos. Retrieved April 4, 2020, from http://www.yogyakartaprinciples.org/principles_ sp.pdf 